\title{
Do lateral dominance, body mass, body height and direction of perturbation influence the Lehr's damping ratio, which characterizes the balancing ability on an unstable oscillatory platform?
}

\author{
R. M. Kiss \\ Dept. of Structures, \\ Budapest University of Technology and Economics, Hungary
}

\begin{abstract}
An unstable oscillatory platform can be used as a simple measuring instrument for modelling balancing capacity. We sought to determine the effects of (1) lateral dominance, (2) body mass, (3) body height and (4) the direction of perturbation on the Lehr's damping ratio for characterizing the balancing ability of 80 healthy young participants on an unstable oscillatory platform. Tests were performed while standing on both limbs and on one limb (dominant or nondominant), and the direction of oscillation was anterior-posterior and mediallateral. The healthy patients were divided into four groups based on body height and into five groups based on body mass. The average value of the Lehr's damping ratio was significantly smaller for participants standing on their nondominant limb compared to their standing on both limbs or on the dominant limb. The largest difference of the Lehr's damping ratio was $0.014(2.5 \%)$ comparing the groups with different body mass, and it was $0.012(2.1 \%)$ comparing the groups with different body height. A weak correlation was found between the Lehr's damping ratio and body mass $(\mathrm{r}=0.14)$ and between the Lehr's damping ratio and body height $(\mathrm{r}=0.19)$. There was a significant difference when comparing the Lehr's damping ratio determined from oscillation in the anterior-posterior direction to the Lehr's damping ratio determined from oscillation in the medial-lateral direction $(\mathrm{p}<0.008)$. Based in our results the
\end{abstract}


Lehr's damping ratio depends on lateral dominance and the direction of perturbation; however, it is independent of body mass and body height. Keywords: ultrasound-based measuring, sudden perturbation, balance.

\section{Introduction}

The measurement of balancing capacity is an important question; most studies concerning balance control have focused mainly on measuring postural balance during quiet standing to be represented by COP (centre of pressure), or COM (centre of mass) position [1, 3-6]. A moving platform is a common method for studying perturbation in balance, and a few previous studies have examined the effect of sinusoidal moving platform translation on postural movement and stability [7-11]. These studies principally examined the linear motion of body segments and the movement of COP and COM relative to the perturbation and involved a wide range of experimental perturbations [12].

Falls regularly occur during gait or following a specific perturbation such as a jump or sudden stop. A high level of complex coordination is required to regain equilibrium after a sudden impulse or a change in direction, either with a static posture (standing, sitting) or during motion (walking, running) [13]. In everyday life, this phenomenon occurs when one is bumped while walking or standing. This effect can be modelled using the PosturoMed ${ }^{\odot}$ (Haider-Bioswing, Weiden, Germany) device, with its moveable and adjustable unstable therapy plates, which is a widely used training and therapy device for neuro-orthopaedic rehabilitation and sports rehabilitation in Europe. The therapy platform can be locked outside of the resting position using the fastening/provocation units. By releasing the fastening/provocation units, the stance equilibrium will be suddenly perturbed [14]. The horizontal movements of the suspended oscillating platform are recorded in two orthogonal directions using a mechanical deflection device (Digimax, Mechatronic, Hamm, Germany) [15-17]. The length of the moving path characterizes balancing capacity, and the shorter moving path represents a better balancing capacity [15-17]. The oscillating platform with an individual on it is a damped system [15]. The motion of the damping system can be represented dynamically by the Lehr's damping ratio $D$ [14]. The Lehr's damping ratio (damping factor) relates the actual damping to the critical damping value at which the system does not oscillate [18]. The Lehr's damping ratio $D$ can be calculated from the movement of the plate recorded as a function of time. The individual balancing ability influences the Lehr's damping ratio. Our earlier research determined the good reliability of the measuring method and of the Lehr's damping ratio for both young and elderly volunteers, and a significant influence of age on the Lehr's damping ratio [14, 19]. The goal of this research was to determine the effects of lateral dominance, body mass, body height and direction of perturbation on the Lehr's damping ratio. 


\section{Materials and methods}

\subsection{Subjects}

Inclusion criteria were age over 18 years and under 40 years for the healthy young group, and the ability to perform independent motion without aids. Each participant's motion range, joint stability, axial position, muscular strength, and muscular tension in the lower limbs were physiologically adequate. Exclusion criteria included any lesion or surgery affecting a lower limb or the lumbar spine in the clinical history; osteoarthritis affecting any joint of a lower limb; neurological alterations (Parkinson, dementia, vertigo, cerebral apoplexy); uncontrolled hypertonia, unstable angina or involvement of the peripheral vestibular system.

The investigation included healthy young men $(n=45$; average age: $24.8 \pm$ $3.5 \mathrm{y}$; average height: $179.9 \pm 14.8 \mathrm{~cm}$; average body mass: $89.4 \pm 9.2 \mathrm{~kg}$, body mass index (BMI): $\left.27.9 \pm 3.4 \mathrm{~kg} / \mathrm{m}^{2}\right)$ and women $(\mathrm{n}=35$; average age: $27.9 \pm$ $6.9 \mathrm{y}$; average height: $169.4 \pm 10.1 \mathrm{~cm}$; average body mass: $70.8 \pm 13.5 \mathrm{~kg}$; BMI: $24.8 \pm 5.7 \mathrm{~kg} / \mathrm{m}^{2}$ ) According to a physical examination performed before motion analysis, the healthy young people were not limited in their everyday motion and sports activities.

Before the test, the dominant side of each participant was determined by a balance recovery test. The subject was nudged off balance from behind by the tester. The perturbation was a nudge applied to the midpoint between the scapulae from directly behind the subject and sufficient to require the subject to respond by taking a step. The leg that the subject used to recover balance was considered the dominant leg for each of the 3 trials. This 3 -test sequence was the same for all subjects [20]. In this research the dominant side was the left side for 12 young healthy subjects and it was the right side for 68 young healthy subjects.

To analyse the effect of body mass, the participants were divided into five groups: under $50 \mathrm{~kg}(\mathrm{n}=3)$, between $50-65 \mathrm{~kg}(\mathrm{n}=22)$, between 66-75 $\mathrm{kg}(\mathrm{n}=35)$, between $76-100 \mathrm{~kg}(\mathrm{n}=16)$ and over $100 \mathrm{~kg}(\mathrm{n}=4)$. To analyse the effect of body height, the participants were divided into five groups: under $150 \mathrm{~cm}(\mathrm{n}=2)$, between 150-170 cm $(n=43)$, between 170-190 cm $(n=28)$, over $190 \mathrm{~cm}(n=7)$. To analyse the effect of the body mass index, the participants were divided into four groups: normal group BMI between 20 and $25 \mathrm{~kg} / \mathrm{m}^{2}(\mathrm{n}=25)$, overweight BMI between 25 and $30 \mathrm{~kg} / \mathrm{m}^{2}(\mathrm{n}=33)$, obese I and II BMI between 30 and 40 $\mathrm{kg} / \mathrm{m}^{2}(\mathrm{n}=13)$, obese II BMI over $40 \mathrm{~kg} / \mathrm{m}^{2}(\mathrm{n}=9)$.

The tests were authorized by the Science and Research Ethics Committee of Semmelweis University (174/2005). Each volunteer provided informed written consent to participation in the tests.

\subsection{Methods}

Sudden changes in direction can be modelled using a commercially available PosturoMed(C) device, which has a rigid plate that is connected to a rigid frame by eight springs of identical strength (Fig. 1). In this research the easiest setting 
is used for the provocation test, where four springs work and four springs are fixed (the spring constant of fixed springs is infinite) $[14,15,17]$.

In this study, the motions of the rigid plate were recorded by single individual markers attached on the side of the rigid plate. The spatial coordinates of markers were measured using a ZEBRIS CMS10 (ZEBRIS, Medizintechnik GmbH, Germany) computer-controlled, ultrasound-based motion analysis system (Fig. 1). The measuring methods are detailed in Kiss [14].

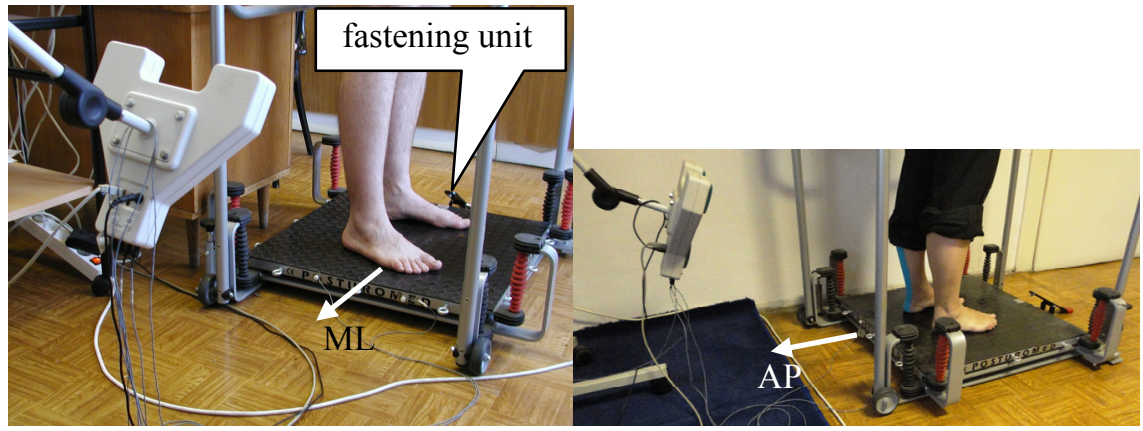

Figure 1: Measurement arrangement a) medial-lateral perturbation (ML) b) anterior-posterior perturbation.

The standardized double-limb stance position for the measurements involved arms hanging freely at the side, with the participant standing barefoot with feet slightly apart at the centre of the platform (position marked by tape). The standardized single-limb stance position for the measurement involved arms hanging freely at the side, the supporting leg barefoot in the centre of the platform (position marked by tape), and the non-supporting leg bent without contacting the supporting leg. Participants were instructed not to watch their motion but instead to look straight ahead. In addition, they were instructed not to hold on to anything but rather to balance with arm motion. They received no warning that the plate would shift. Each participant wore a safety harness, part of the PosturoMed device, that allowed natural arm motion. If a participant touched either a hand or the non-supporting leg to the guardrail or the platform or if the supporting leg was moved from the starting position, the trial was rejected.

The first measurement was carried out on the double-leg stance, followed by measurement on the dominant leg and then the non-dominant leg stance using medial-lateral perturbation. The platform was moved $20 \mathrm{~mm}$ in a medial-lateral direction towards the dominant side and locked by a fastening unit. All trials were then repeated under the anterior-posterior perturbation, where the platform was moved $20 \mathrm{~mm}$ in an anterior-posterior direction towards anterior side and locked by a fastening unit. The participants took up the standardized measuring position and stood for $2 \mathrm{~s}$, after which the fastening unit was released to perturb the stance equilibrium. Three $3 \mathrm{~s}$ measurements were carried out for each measuring position. There were $60 \mathrm{~s}$ rest intervals between measurements. The average value of successfully completed trials was taken as the value for each 
measuring position, and a minimum of two successfully completed trials was required for each measuring position.

The oscillated PosturoMed ${ }^{\odot}$ device with a participant on it is a damped system $[14,19]$. The damped system can be characterized by the Lehr's damping ratio (damping ratio, ratio $\mathrm{D}$, damping factor), which can be calculated from the measured damped curve (Fig. 2) [14, 19].

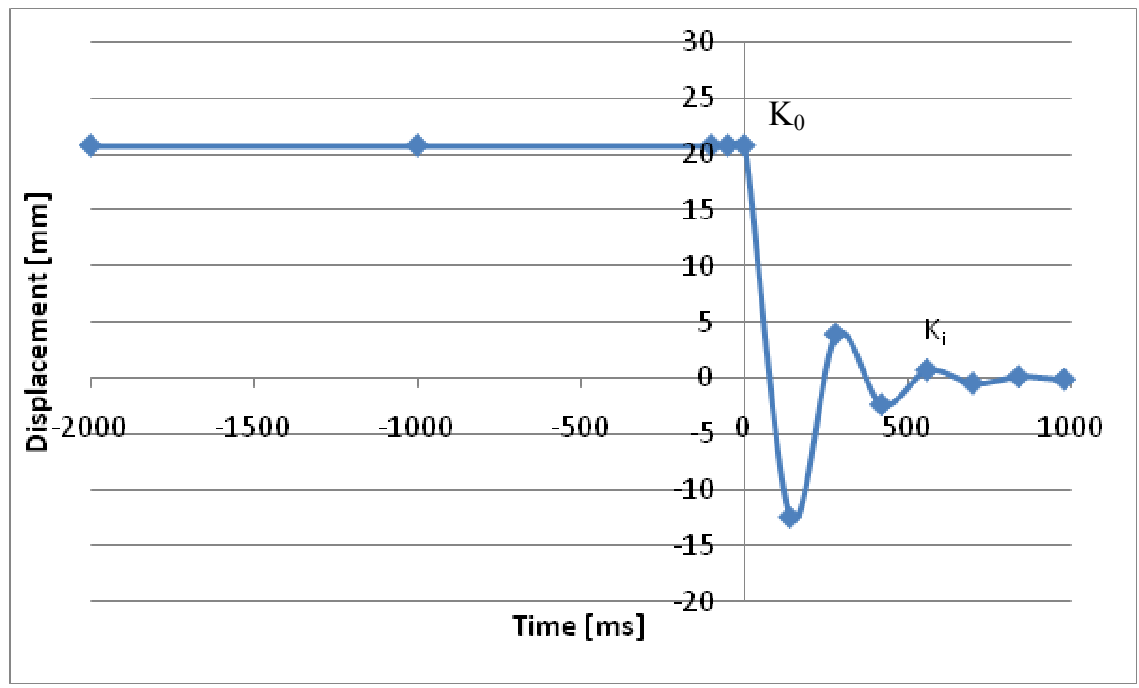

Figure 2: $\quad$ Measured damping curve.

$$
D=\frac{\Lambda}{\sqrt{\Lambda^{2}+4 \pi^{2}}},
$$

where $\pi=$ is 3.14 ;

$$
\Lambda=\text { is the logarithmic decrement, } \Lambda_{i}=\frac{1}{i} \ln \frac{K_{0}}{K_{i}},
$$

where $K_{0}$ is the amplitude at time $t=t_{0}$, and $K_{i}$ is the amplitude at time $t=t_{i \cdot 0}$ as measured by the ultrasound-based system.

The Lehr's damping ratios for individuals within a given group were statistically analysed using the MS Excel Analysis Tool Pak software. The average and standard deviation were calculated, and the homogeneity of variance was checked by an F-test. To analyse the influence of dominance and direction of perturbation on balancing ability, the one-sample t-test applying a symmetrical critical range was used. To analyse the effect of body mass, body height, and BMI on balancing ability, the two-sample t-test was used and the ratio - the two-tailed Pearson product-moment correlation coefficient $(r)$ - was calculated between the Lehr's damping ratio and the body mass or body height. The significance level was $p \leq 0.05$. 


\section{Results}

Each volunteer managed to complete all three parts of the tests; thus, no exclusions occurred for incomplete results. The F-test demonstrated the uniformity of standard deviations. The Lehr's damping ratio was between 0 and 1 in all cases where the motion of the rigid plate was a damping movement. Table 1 provides a summary of the results. There were no significant differences between the average values of the Lehr's damping ratio of male subjects and of female subjects ( $p>0.14)$; of the subjects with different body mass ( $>0.11)$, and subjects with different body height $(\mathrm{p}>0.19)$ (Table 1).

No significant difference was found comparing the average values of the Lehr's damping ratio of subjects with different BMI $(\mathrm{p}>0.09)$, except for the values of subjects with normal BMI $\left(20-25 \mathrm{~kg} / \mathrm{m}^{2}\right)$ compared to the values of subjects with obese III BMI $\left(>40 \mathrm{~kg} / \mathrm{m}^{2}\right)(\mathrm{p}<0.03)$ (Table 1). The Pearson correlation was very weak between the Lehr's damping ratio and body mass $(\mathrm{r}=0.19)$ and between the Lehr's damping ratio and body height $(\mathrm{r}=0.14)$.

The average value of the Lehr's damping ratio determined while the participants stood on their non-dominant limb was significantly smaller than it was while they stood on both of their limbs $(p=0.006)$ or standing on their dominant limb $(p=0.001)$ (Table 1$)$. There was no significant difference between the average values of the Lehr's damping ratio determined while participants were standing on the dominant limb compared to those determined while participants were standing on both limbs ( $p=0.139$ for the young group) (Table 1).

The direction of perturbation significantly influenced the values of the Lehr's damping ratio; the value of the Lehr's damping ratio was significantly higher if the direction of perturbation was anterior-posterior $(p<0.008)$ (Table 1).

\section{Discussion}

On the basis of the results above, it can be established that the effect of body mass, body height, BMI and sex was very low (Table 1). The Lehr's damping ratio increased with the increasing of body mass; however, the difference is not significant. This was confirmed by the weak correlation between the Lehr's damping ratio and body mass $(\mathrm{r}=0.19)$. The tendency is not linear between the Lehr's damping ratio and body height, which is confirmed by a very weak correlation $(\mathrm{r}=0.14)$. Maki and McIlroy [1] established that balancing capacity is a result of a complex control mechanism in which the effect of body mass and body height is negligible compared to neurological, proprioceptive parameters and to age. Blaszczyk et al. [22] established that postural control was significantly decreased only at female subjects with BMI over $40 \mathrm{~kg} / \mathrm{m}^{2}$. Our results agree with this trend, because a significant difference was found at male and female subjects with BMI over $40 \mathrm{~kg} / \mathrm{m}^{2}$ (Table 1).

Lateral dominance influenced balancing capacity on an unstable oscillatory platform after sudden perturbation. For both groups in the current work, the Lehr's damping ratio calculated during standing on both limbs did not differ 
Table 1: $\quad$ Average \pm standard deviation of Lehr's damping ratio $(D)$.

\begin{tabular}{|c|c|c|c|c|c|c|c|}
\hline & & \multicolumn{3}{|c|}{ Medial-lateral provocation } & \multicolumn{3}{|c|}{ Anterior-posterior provocation } \\
\hline & & \multicolumn{3}{|c|}{ standing on } & \multicolumn{3}{|c|}{ standing on } \\
\hline & & $\begin{array}{l}\text { both } \\
\text { limbs }\end{array}$ & $\begin{array}{l}\text { dominant } \\
\operatorname{limb}\end{array}$ & $\begin{array}{c}\text { non- } \\
\text { dominant } \\
\text { limb }\end{array}$ & $\begin{array}{l}\text { both } \\
\text { limbs }\end{array}$ & $\begin{array}{c}\text { dominant } \\
\operatorname{limb}\end{array}$ & $\begin{array}{c}\text { non- } \\
\text { dominant } \\
\text { limb }\end{array}$ \\
\hline \multirow{2}{*}{ ळे } & $\begin{array}{l}\text { male } \\
n=45\end{array}$ & $\begin{array}{c}0.543 \pm \\
0.031\end{array}$ & $\begin{array}{c}0.530 \pm \\
0.027\end{array}$ & $\begin{array}{c}0.418 \pm \\
0.015^{\dagger, 末}\end{array}$ & $\begin{array}{l}0.597 \pm \\
0.025^{*}\end{array}$ & $\begin{array}{l}0.590 \pm \\
0.020^{*}\end{array}$ & $\begin{array}{c}0.502 \pm \\
0.011^{\dagger, t, *}\end{array}$ \\
\hline & $\begin{array}{c}\text { female } \\
n=35\end{array}$ & $\begin{array}{c}0.539 \pm \\
0.029\end{array}$ & $\begin{array}{c}0.525 \pm \\
0.023\end{array}$ & $\begin{array}{c}0.417 \pm \\
0.017^{\dagger, 4}\end{array}$ & $\begin{array}{l}0.594 \pm \\
0.027^{*}\end{array}$ & $\begin{array}{l}0.588 \pm \\
0.019^{*}\end{array}$ & $\begin{array}{c}0.499 \pm \\
0.013^{\dagger, \ddagger}, * \\
\end{array}$ \\
\hline \multirow{5}{*}{$\begin{array}{l}\text { है } \\
\vdots \\
\vdots \\
\vdots \\
\vdots \\
0\end{array}$} & $\begin{array}{c}<50 \mathrm{~kg} \\
n=3\end{array}$ & $\begin{array}{c}0.535 \pm \\
0.030 \\
\end{array}$ & $\begin{array}{c}0.523 \pm \\
0.026\end{array}$ & $\begin{array}{c}0.415 \pm \\
0.014^{\dagger, 末}\end{array}$ & $\begin{array}{l}0.589 \pm \\
0.026^{*}\end{array}$ & $\begin{array}{l}0.584 \pm \\
0.021^{*}\end{array}$ & $\begin{array}{c}0.491 \pm \\
0.013^{\dagger, \ddagger, *}\end{array}$ \\
\hline & $\begin{array}{c}50-65 \mathrm{~kg} \\
n=22\end{array}$ & $\begin{array}{c}0.537 \pm \\
0.029 \\
\end{array}$ & $\begin{array}{c}0.526 \pm \\
0.025\end{array}$ & $\begin{array}{l}0.416 \pm \\
0.016^{\dagger, 末}\end{array}$ & $\begin{array}{l}0.593 \pm \\
0.024^{*} \\
\end{array}$ & $\begin{array}{l}0.585 \pm \\
0.019^{*}\end{array}$ & $\begin{array}{c}0.494 \pm \\
0.011^{\dagger, \ddagger, *}\end{array}$ \\
\hline & $\begin{array}{c}66-75 \mathrm{~kg} \\
n=35\end{array}$ & $\begin{array}{c}0.541 \pm \\
0.027\end{array}$ & $\begin{array}{c}0.527 \pm \\
0.023\end{array}$ & $\begin{array}{c}0.417 \pm \\
0.019^{\dagger, \text { 束 }}\end{array}$ & $\begin{array}{l}0.595 \pm \\
0.020^{*}\end{array}$ & $\begin{array}{l}0.587 \pm \\
0.017^{*}\end{array}$ & $\begin{array}{c}0.497 \pm \\
0.012^{\dagger,+, *}\end{array}$ \\
\hline & $\begin{array}{c}76-100 \mathrm{~kg} \\
n=16\end{array}$ & $\begin{array}{c}0.545 \pm \\
0.027 \\
\end{array}$ & $\begin{array}{c}0.533 \pm \\
0.021\end{array}$ & $\begin{array}{l}0.420 \pm \\
0.015^{\dagger,}\end{array}$ & $\begin{array}{l}0.598 \pm \\
0.027^{*} \\
\end{array}$ & $\begin{array}{l}0.590 \pm \\
0.018^{*}\end{array}$ & $\begin{array}{c}0.500 \pm \\
0.013^{\dagger, \ddagger, *}\end{array}$ \\
\hline & $\begin{array}{c}>100 \mathrm{~kg} \\
n=4\end{array}$ & $\begin{array}{c}0.549 \pm \\
0.026 \\
\end{array}$ & $\begin{array}{c}0.537 \pm \\
0.030 \\
\end{array}$ & $\begin{array}{c}0.419 \pm \\
0.017^{\dagger,}\end{array}$ & $\begin{array}{l}0.599 \pm \\
0.028^{*} \\
\end{array}$ & $\begin{array}{c}0.597 \pm \\
0.019^{*}\end{array}$ & $\begin{array}{c}0.502 \pm \\
0.015^{\dagger, 末 * *}\end{array}$ \\
\hline \multirow{4}{*}{ 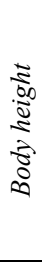 } & $\begin{array}{c}<150 \mathrm{~cm} \\
n=2\end{array}$ & 0.541 & 0.528 & 0.420 & 0.596 & 0.592 & 0.497 \\
\hline & $\begin{array}{c}150-170 \mathrm{~cm} \\
n=43\end{array}$ & $\begin{array}{c}0.539 \pm \\
0.033\end{array}$ & $\begin{array}{c}0.527 \pm \\
0.029\end{array}$ & $\begin{array}{c}0.416 \pm \\
0.019^{\dagger, 末}\end{array}$ & $\begin{array}{l}0.593 \pm \\
0.024^{*}\end{array}$ & $\begin{array}{l}0.589 \pm \\
0.021^{*}\end{array}$ & $\begin{array}{c}0.501 \pm \\
0.012\end{array}$ \\
\hline & $\begin{array}{c}171-190 \mathrm{~cm} \\
n=28\end{array}$ & $\begin{array}{c}0.545 \pm \\
0.021 \\
\end{array}$ & $\begin{array}{c}0.533 \pm \\
0.023\end{array}$ & $\begin{array}{c}0.419 \pm \\
0.016^{\dagger, 末}\end{array}$ & $\begin{array}{l}0.601 \pm \\
0.022^{*}\end{array}$ & $\begin{array}{l}0.596 \pm \\
0.018^{*}\end{array}$ & $\begin{array}{c}0.503 \pm \\
0.011^{\dagger, \ddagger, *}\end{array}$ \\
\hline & $\begin{array}{c}>190 \mathrm{~cm} \\
n=7\end{array}$ & $\begin{array}{c}0.533 \pm \\
0.020 \\
\end{array}$ & $\begin{array}{c}0.524 \pm \\
0.018\end{array}$ & $\begin{array}{l}0.420 \pm \\
0.012^{\dagger, 末}\end{array}$ & $\begin{array}{l}0.588 \pm \\
0.023^{*} \\
\end{array}$ & $\begin{array}{l}0.582 \pm \\
0.014^{*}\end{array}$ & $\begin{array}{c}0.506 \pm \\
0.011^{\dagger, \ddagger, *}\end{array}$ \\
\hline \multirow{4}{*}{$\underset{\infty}{\nexists}$} & $\begin{array}{c}20-25 \mathrm{~kg} / \mathrm{m}^{2} \\
n=25\end{array}$ & $\begin{array}{c}0.537 \pm \\
0.028\end{array}$ & $\begin{array}{c}0.525 \pm \\
0.025\end{array}$ & $\begin{array}{c}0.408 \pm \\
0.015^{\dagger,}\end{array}$ & $\begin{array}{l}0.587 \pm \\
0.020^{*}\end{array}$ & $\begin{array}{l}0.582 \pm \\
0.019^{*}\end{array}$ & $\begin{array}{c}0.492 \pm \\
0.012^{\dagger, \star, *}\end{array}$ \\
\hline & $\begin{array}{c}25-30 \mathrm{~kg} / \mathrm{m}^{2} \\
n=33\end{array}$ & $\begin{array}{c}0.540 \pm \\
0.033\end{array}$ & $\begin{array}{c}0.530 \pm \\
0.030\end{array}$ & $\begin{array}{c}0.416 \pm \\
0.017\end{array}$ & $\begin{array}{l}0.595 \pm \\
0.023^{*}\end{array}$ & $\begin{array}{l}0.588 \pm \\
0.020^{*}\end{array}$ & $\begin{array}{c}0.497 \pm \\
0.014^{\dagger, \star, *}\end{array}$ \\
\hline & $\begin{array}{c}30-40 \mathrm{~kg} / \mathrm{m}^{2} \\
n=13\end{array}$ & $\begin{array}{c}0.549 \pm \\
0.031\end{array}$ & $\begin{array}{c}0.538 \pm \\
0.028\end{array}$ & $\begin{array}{c}0.420 \pm \\
0.019^{\dagger, \ddagger}\end{array}$ & $\begin{array}{l}0.599 \pm \\
0.027^{*} \\
\end{array}$ & $\begin{array}{l}0.592 \pm \\
0.021^{*}\end{array}$ & $\begin{array}{c}0.504 \pm \\
0.013^{\dagger, \downarrow, *} \\
\end{array}$ \\
\hline & $\begin{array}{c}>40 \mathrm{~kg} / \mathrm{m}^{2} \\
n=9\end{array}$ & $\begin{array}{l}0.564 \pm \\
0.037^{\#}\end{array}$ & $\begin{array}{l}0.540 \pm \\
0.036^{\#}\end{array}$ & $\begin{array}{l}0.424 \pm \\
0.020^{\dagger,+, \# ~}\end{array}$ & $\begin{array}{l}0.604 \pm \\
0.029^{*, \#}\end{array}$ & $\begin{array}{l}0.599 \pm \\
0.024^{*}\end{array}$ & $\begin{array}{l}0.507 \pm \\
0.016^{\dagger, \grave{,}, * \#}\end{array}$ \\
\hline
\end{tabular}

${ }^{\dagger}$ Significant difference between the average values of parameters compared to parameters measured during standing on both limbs.

"Significant difference between the average values of parameters compared to parameters measured during standing on the dominant limb.

* Significant difference between the average values of parameters measured with medial-lateral perturbation compared to the parameters measured anterior-posterior perturbation.

\# Significant difference between the average values of parameters of subjects with normal BMI $\left(20-25 \mathrm{~kg} / \mathrm{m}^{2}\right)$ compared to the parameters of subjects with obese III BMI $\left(>40 \mathrm{~kg} / \mathrm{m}^{2}\right)$.

significantly from the value calculated during standing on the dominant limb. However, the results obtained during standing on the non-dominant limb did differ significantly from those of the other two tests. Boeer et al. [16] and Müller et al. [15] showed that the total path of the moving plate representing balancing capacity on an unstable oscillatory platform depends on lateral dominance. Our measurement results provide further confirmation because the Lehr's damping ratio indicated a dependence on lateral dominance. 
Another new finding from the current research is that the direction of perturbation significantly affects balancing capacity on an unstable oscillatory platform after sudden perturbation, as characterized by the Lehr's damping ratio. Boeer et al. [16] demonstrated that the path length of an oscillatory platform after sudden disturbance standing on single limb was significantly decreased if the direction of perturbation was anterior-posterior. Our results confirmed these findings for standing on single and double limbs, because the values of the Lehr's damping ratio during standing on both limbs or on a single limb significantly increased if the direction of perturbation was anterior-posterior (Table 1). The difference can be traced back to a difference in neuromuscular control mechanisms of motion in the anterior-posterior and medial-lateral directions, which are discussed partly differently $[15,16]$. Our results confirmed that the neuromuscular control mechanism is better in anterior-posterior motion.

The provocation test can model complex balancing capacity because after dislocation, the fastening unit locks the platform, and after release, the platform starts to return suddenly to its original position, representing a sudden perturbation [14]. The results in the current work show that lateral dominance and the direction of perturbation significantly affect balancing capacity on an unstable oscillatory platform after sudden perturbation; however, the effect of body mass and body height is negligible. On the basis of our results it can be established that the stabilization of the oscillated platform, characterized by the Lehr's damping ratio, is the result of the control mechanism of the neuromuscular system. Finally, this study extends knowledge because of its expanded study populations: different effects on the Lehr's damping ratio were determined by analysing data for 80 healthy young volunteers. Indeed, this method is used on a day-to-day basis at the Biomechanical Laboratory of MÁV Hospital at Szolnok and at the Department of Orthopaedics of Semmelweis University.

\section{Acknowledgements}

This work is connected to the scientific program of the "Development of qualityoriented and harmonized $\mathrm{R}+\mathrm{D}+\mathrm{I}$ strategy and functional model at BME" project. This project is supported by the New Hungary Development Plan (Project ID: TÁMOP-4.2.1/B-09/1/KMR-2010-0002). This work was supported by the Hungarian Scientific Fund T083650. Special thanks to Professor Kocsis for advice and help and to Árpád Illyés MD PhD, Zoltán Bejek MD, Gergely Holnapy MD, Maria Takacs MD and Ákos Pethes MD for their help in completing the measurements.

\section{References}

[1] Maki, B.E. \& McIlroy, W.E., Postural control in the older adults. Clinics in Geriatric, 12, pp. 635-658, 1996.

[2] Prieto, T.Y., Myklebust, J.B., Hoffmann, R.G., Lovett, E.G., \& Myklebust, B.M., Measures of postural steadiness: differences between healthy young 
and elderly adults. IEEE Transaction on Biomedical Engineering, 43, pp. 956-966, 1996.

[3] Newell, K.M., van Emmerik, R.E.A., Lee, D. \& Sparague, R.L., On postural stability and variability. Gait and Posture, 1, pp. 225-230, 1993.

[4] Yamada, N. Chaotic swaying of the upright posture. Human Movement Science, 14, pp. 711-736, 1995.

[5] Riley, M.A., Balasubramaniam, R. \& Turvay, M.T., Recurrence quantification analysis of postural fluctuation. Gait and Posture, 9, pp. 65$78,1999$.

[6] Donker, S.F., Roerding, M., Greven, A.J. \& Beek, P.J., Regularity of center of pressure trajectories depends on the amount of attention invested in postural control. Experimental Brain Research 181, pp. 1-11, 2007.

[7] Berger, W., Discher, M., Trippel, M., Ibrahim, I.K. \& Dietz, V., Developmental aspects of stance regulation, compensation and adaptation. Experimental Brain Research 90, pp. 610-619, 1992.

[8] Buchanan, J.J. \& Horak, F.B., Emergence of postural pattern as a function of vision and translation frequency. Journal of Neurophysiology 81, pp. 2325-2339, 1999.

[9] Corna, S., Tarantola, J., Nardone, A., Giordano, A. \& Schiepati, M., Standing on a continuously moving platform: Is body inertia counteracted or exploited? Experimental Brain Research, 124, pp. 331-341, 1999.

[10] Diener, H.C., Dichgans, J., Bruzek, W. \& Selinka, H., Stabilization of human posture during induced oscillation of the body. Experimental Brain Research, 45, pp. 126-132, 1982.

[11] Dietz, V., Trippel, M., Ibrahim, I.K. \& Berger, W., Human stance on a sinusoidally translating platform: balance control by feed forward and feedback mechanism. Experimental Brain Research 93, pp. 352-362, 1993.

[12] Ko, Y.G., Challis, J.H. \& Newell, K.M., Postural coordination patterns as a function of dynamics of the support surface. Human Movement Science, 20, pp.737-764, 2001.

[13] Winter, D.A., ABC of balance during standing and walking. Waterloo: Waterloo Biomechanics, 1995.

[14] Kiss, R.M., Parameters of kinaesthesis during gaits derived from an ultrasound-based measuring system. Modelling in medicine and biology VIII eds. C.A. Brebbia, WIT Press: Wessex, pp. 171-180, 2009

[15] Müller, O., Günther, M., Krauß, I. \& Horstman, T., Physical characterization of the therapeutic device Posturomed as a measuring device-Presentation of a procedure to characterize balancing ability. Biomedizinishe Technik, 49, pp. 56-60, 2004.

[16] Boeer, J., Mueller, O., Krauß, I., Haupt, G. \& Horstman, T., Reliability of a measurement technique to characterize standing properties and to quantify balance capabilities of healthy subjects on an unstable oscillatory platform (Posturomed). Sportverletz Sportschaden 24, pp. 40-45, 2010.

[17] Boeer, J., Mueller, O., Krauß, I., Haupt, G., Axmann, D. \& Horstman, T., Effect of a Sensory-motor exercise program for older adults with osteoarthritis or prothesis of the hip using measurements made by 
Posturomed oscillatory platform. Journal of Geriatric Physical Therapy, 33, pp. 10-15, 2010.

[18] Hubbeler, R.C., Engineering Mechanics: Dynamics. Prentice Hall: New Jersey, 1999.

[19] Kiss, R.M., A new parameter for characterizing balancing ability on an unstable oscillatory platform. Medical Engineering and Physics, (under publishing), 2011.

[20] Hoffman, M., Schrader, J., Applegate, T. \& Koceja, T., Unilateral postural control of the functionally dominant and nondominant extremities of healthy subjects. Journal of Athletic Training, 33, pp. 319-322, 1998.

[21] Kiss, R.M., Kocsis, L. \& Knoll, Z, Joint kinematics and spatial temporal parameters of gait measured by an ultrasound based system. Medical Engineering \&Physics 26, pp. 611-620, 2004.

[22] Blaszczyk, J.W., Cielinska-Swider, J., Plewa, M., Zahorska-Markiewicz, B. \& Markiewicz, A., Effects of excessive body weight on postural control. Journal of Biomechanics, 42, pp. 1295-1300, 2009.

[23] Morasso, P.G. \& Schieppati, M. Can muscle stiffness alone stabilize upright standing? Journal of Neurophysiology, pp. 1622-1626, 1996.

[24] Winter, D.A., Prince, F., Frank, J.S., Powell, C. \& Zabjek, K.F., Unified theory regarding AP and ML balance in quiet stance. Journal of Neurophysiology, pp. 2334-2343, 1996. 